This is the accepted manuscript, and which has been accepted by IEEE for publication. (C) 2010 IEEE. Personal use of this material is permitted. Permission from IEEE must be obtained for all other uses, in any current or future media, including reprinting/republishing this material for advertising or promotional purposes, creating new collective works, for resale or redistribution to servers or lists, or reuse of any copyrighted component of this work in other works. The full reference is:

\title{
'Electrical and Material Characterization of Field-Aged 400 kV Silicone Rubber Composite Insulators'
}

\author{
S. M. Rowland, J. Robertson, Y. Xiong, and R.J. Day
}

IEEE Transactions on Dielectrics and Electrical Insulation, Vol. 17, Issue 2, pp. 375-383, April 2010

Digital Object Identifier: 10.1109/TDEI.2010.5448091 


\title{
Electrical and Material Characterization of Field-aged 400 kV Silicone Rubber Composite Insulators
}

\author{
S. M. Rowland, J. Robertson, Y. Xiong, \\ The School of Electrical and Electronic Engineering, \\ The University of Manchester, PO Box 88, Manchester, M60 1QD, UK \\ and R.J. Day \\ Northwest Composites Centre, School of Materials, \\ The University of Manchester, PO Box 88, Manchester, M60 1QD, UK
}

\begin{abstract}
This paper presents the electrical and material characteristics of field-aged silicone rubber composite insulators, which have been deployed for 15 years on a $400 \mathrm{kV}$ transmission line in a coastal region of the UK. There were no indications of reduced performance in service. Observations indicate non-uniform aging of the insulators on the different surfaces of the insulator sheds and core, along the insulator string length and in the different compass orientations. A uniquely large number of contact angle measurements, made on each of the insulators' different surfaces, confirm the visual aspect of non-uniform aging. Electrical investigations of the insulators have been performed in terms of leakage current analysis, ac flashover / withstand and switchingsurge impulse flashover. A correlation is seen between the ac leakage current and the hydrophobicity measurements. Energy dispersive X-ray (EDX) and Fourier transform infrared spectroscopy (FTIR) analysis of the changes of the materials' surface chemistry is presented. The role of solar radiation and organic growth appears critical to the observed non-uniform aging and must be considered if the longer term operation of the insulator is to be forecast. It is proposed that a reduction of the difference between positive and negative wet-flashover voltages may be a good indicator of early insulator aging.
\end{abstract}

Index Terms - Silicone rubber, composite, insulators, hydrophobicity, contact angle, aging mechanisms, transmission line, NCI, impulse flashover.

\section{INTRODUCTION}

COMPOSITE insulators have been used around the world on overhead lines since they were introduced in the 1960s. Early composite insulators failed due to poor design, manufacturing processes or application. However, the market for such insulators has now existed for over 20 years and improved design and manufacturing techniques have overcome problems seen in early applications. In the following three decades composite insulators have found rapidly increasing usage throughout the world.

Composite insulators have advantages over glass and porcelain insulators due to ease of installation, lightweight construction, and vandal resilience. In addition, silicone rubber based insulators have superior performance in heavily polluted environments [1].

Counter to these benefits, a comprehensive understanding of the insulators long-term performance is yet to be realized, due to the impact of different electrical and environmental aging mechanisms. Environmental aging factors, include: ultra violet (UV) radiation from sunlight, organic growth, acid rain and ozone. Electrical aging factors consist primarily of corona, from water droplets or metallic fittings, and dry-band arcing. The interaction between environmental and electrical aging factors is complex and not fully understood [2].

Aging of insulation surfaces manifests itself in terms of a degradation in hydrophobicity and is key to the performance of the material under wet conditions. When a material is in a highly hydrophobic state, water forms discrete droplets on the surface of the insulation with high contact angles. As the polymeric material becomes aged, the hydrophobicity of the material is degraded and becomes hydrophilic in nature, allowing water droplets to form with low contact angles, which in extreme circumstances form layers of water on the insulation surface.

Failure of composite insulators can be described in terms of two failure modes. The first failure mode is due to a loss in tensile strength of the insulator, which may occur once the outer sheath of the insulator core has been punctured, allowing water migration and discharge activity to take place in the insulator strength member. The second failure 
mode may be defined through high electrical flashover statistics, under operational conditions.

Aging effects, including a decrease in the hydrophobicity of the material, can play a role in both of these failure modes. Under wet conditions, a decrease in the hydrophobicity of the material allows conductive currents to flow over the insulator surface and may change the electric field distribution along the insulator string. Localized field enhancements in dry regions of the insulator string may allow dry-band arcing to take place. Depending on the magnitude of the leakage currents, an erosion process may occur on the insulator surface as a result. Due to the cross-sectional area of the insulator core and the resulting magnitude of current densities, this region is most prone to these effects. Surface contamination through salt and other deposits may also influence the magnitude of the currents in the dry-band arc. Previous research has shown that currents in the region of $10 \mathrm{~mA}$ are most damaging to the insulator surfaces $[3,4]$.

On a macroscopic level, the distortion in electric field distribution along the string, caused by high leakage currents, can lead to a reduction in the flashover voltage of the insulators, particularly under transient conditions [5].

This paper presents a report on the natural field aging of silicone rubber composite insulators. An assessment of the different types of aging has initially been performed through visual observations and hydrophobicity analysis. The effect on the electrical performance is then presented through laboratory electrical tests. The deterioration in the electrical performance of the insulators has been analyzed through impulse and ac flashover statistics as well as leakage current characteristics. Analysis of the change in the materials surface chemistry through EDX and FTIR has also been performed.

\section{LINE TOPOLOGY, VISUAL OBSERVATIONS AND HYDROPHOBICITY}

18 composite insulators were removed from a $400 \mathrm{kV}$ twin circuit overhead transmission line which had been in service in a field trial in the southwest of England for 15 years. Details of the location of this field trial have been described previously [6].

Each of the insulators consists of 72 identical silicone rubber sheds, which have been high-temperature vulcanized onto an extruded core. The overall length of the insulator is $3.35 \mathrm{~m}$, with a dry flashover distance of $3.05 \mathrm{~m}$ and a creepage distance $10.23 \mathrm{~m}$. This creepage distance results in a creepage distance to electrical stress ratio of $44.3 \mathrm{~mm} / \mathrm{kVrms}$ equivalent to $22.6 \mathrm{Vrms} / \mathrm{mm}$

Visual observations indicate that non-uniform aging had taken place. Differences in the aged surfaces are seen from the top to the bottom of the insulator string, on the different insulator sheds and core surfaces and in different compass orientations. Despite showing signs of aging, the insulators' present state did not show any severe erosion or surface cracking making them unfit for further use.

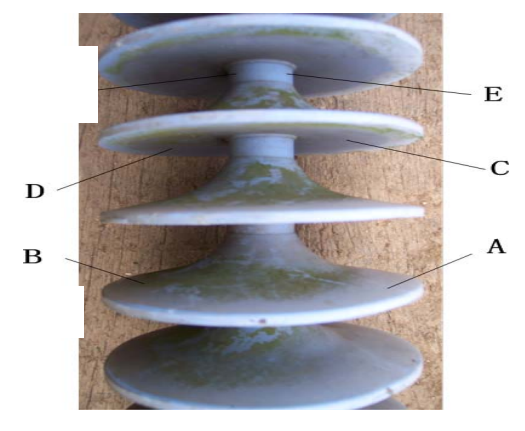

Figure 1. Visual aging observations are typified by regions A - E.

The bottom area near the high voltage (HV) end was covered by thicker contaminant than other areas along the string. The contaminant created a robust 'skin' on the original surface.

Visual observations indicate rotational asymmetry. Southern facing shed surfaces, (labeled A in Figure 1) which have been exposed to the sunlight, have become bleached, whilst northern facing surfaces, (labeled B and D in Figure 1) have a high degree of organic contamination on the surfaces. More obvious pollution layers are evident near $\mathrm{HV}$ and low voltage (LV) end-fittings. White rings (labeled $\mathrm{C}$ in Figure 1) on the outer bottom surfaces of sheds have been observed on several of the insulators. Discoloration of the insulator core (labeled E in Figure 1) has not occurred, however signs of a white residue are evident.

To assess the degree of hydrophobicity on the different insulator surfaces, contact angle measurement were carried out on all 18 strings. Measurements were made on 11 of the 72 sheds evenly distributed along the strings. For each shed, measurements were made on both the bottom and top surfaces in the four compass orientations. Contact angle analysis was performed with the insulator in a vertical orientation (upside down for the bottom surfaces). The receding angle of inclination of the top and bottom surfaces of the sheds were determined to be $10.6^{\circ}$ and $7.4^{\circ}$ respectively. Figures 2 and 3 show the average contact angle on the top and bottom shed surfaces along the insulator strings, respectively. The lines in these figures represent best fit second order polynomials. The arrows indicate the typical spread of results ( $\max$ and $\min$ ) around the average values plotted. These figures illustrate lower contact angle measurements on the exposed southern top and bottom surfaces of the insulator sheds than on northern facing surfaces. Shed surfaces in the mid-section of the string also indicated lower contact angles than the sections near the LV and HV ends.

Comparing top and bottom shed surfaces, the lowest hydrophobicity values measured were on the southernfacing shed top surfaces. This is indicative of a greater degree of aging on the top surfaces of the sheds. The highest values of contact angles were seen at the bottom, north-facing, $\mathrm{HV}$ end of the string, and associated with 
higher levels of surface pollution, believed to be organic growth. More detail of these observations is given in $[6,7]$.

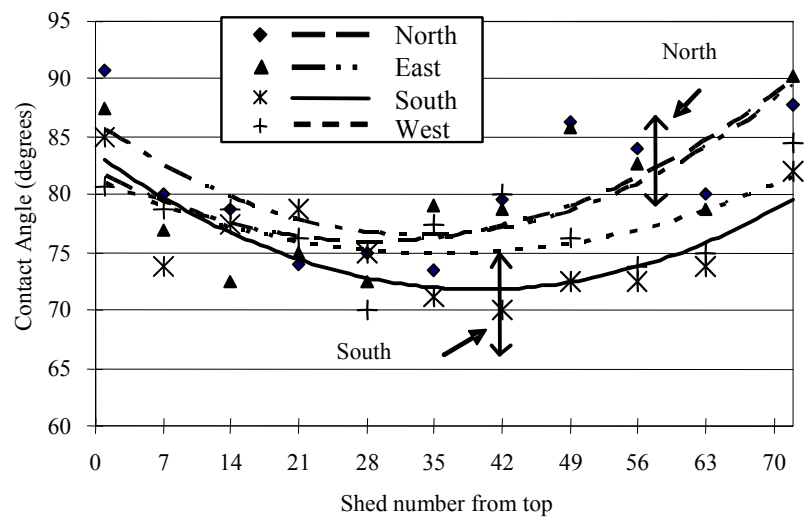

Figure 2. Average contact angle on the top surface along the strings.

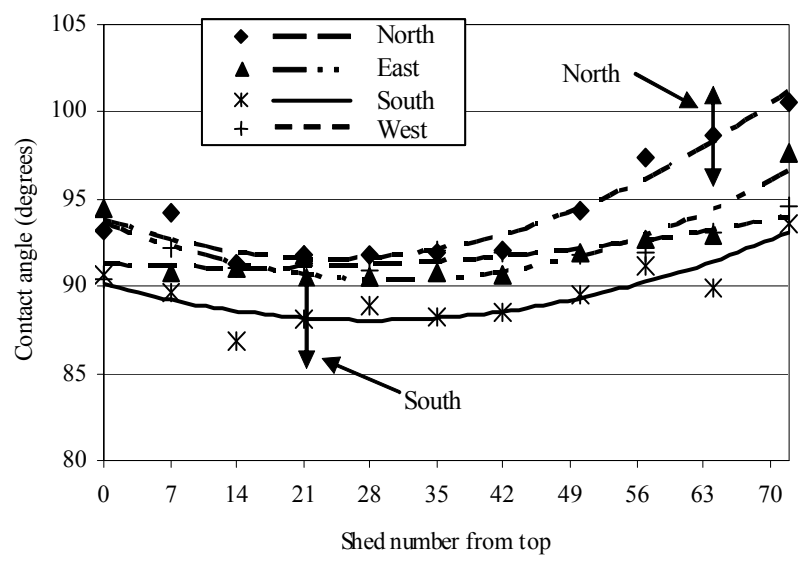

Figure 3. Average contact angle on the bottom surface along the strings

\section{ELECTRICAL TESTING}

To correlate the deterioration in electrical performance with the variation in hydrophobicity along the insulator string, the strings were divided up into $1 / 3$-sections (24 sheds) using domed electrodes, as illustrated in Figure 4. Three types of electrical tests were performed on the string sections: $250 \mu \mathrm{s} / 2.5 \mathrm{~ms}$ impulse flashover investigations, ac withstand / flashover, and ac leakage current measurements. These tests were carried out under both dry and wet spray conditions to IEC 60060 [7]. The results for the field-aged insulator were compared to a similar new insulator string.

\section{1 $250 \mu \mathrm{s} / 2.5 \mathrm{~ms}$ Switching Surge Impulse Flashover Investigations}

$250 \mu \mathrm{s} / 2.5 \mathrm{~ms}$ switching surge impulse tests were performed using a $2 \mathrm{MV}$ Haefely impulse generator. For each polarity, the $\mathrm{V}_{50}$ flashover level was determined using an up-down method from a series of at least 25 impulses, of which at least 10 impulses flashed over and withstood the applied impulse. Table 1 shows the impulse flashover statistics for both new and field-aged insulators under dry and wet test conditions.

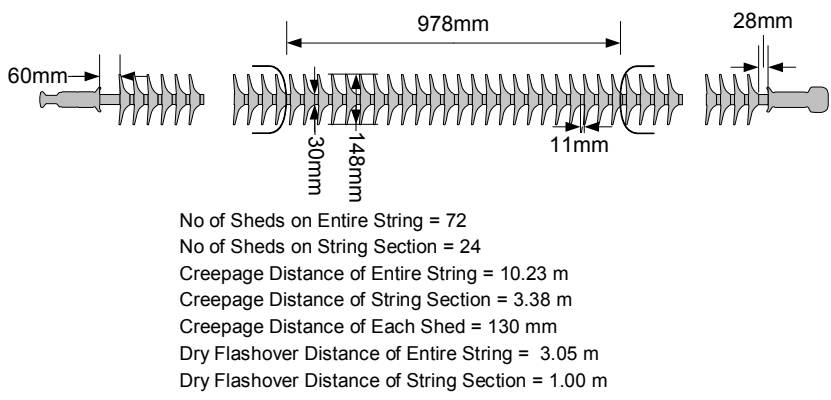

Figure 4. $1 / 3$ Insulator string sections used in electrical tests

Table 1 shows the mean, the standard deviation $(\sigma)$, and the largest and smallest values (max and min) measured of $\mathrm{V}_{50}$. As would be expected, for both the new and the fieldaged insulators, the dry negative polarity impulse level is much larger than the dry positive polarity impulse level. For new insulators, tested under wet conditions, despite there being a greater percentage decrease in the negative polarity impulse level than the positive polarity impulse level, this relationship still remains true. The probability distribution of the $\mathrm{V}_{50}$ impulse flashover levels for all the new insulator string sections is shown in Figure 5.

For field-aged insulators, however, the positive and negative polarity impulse flashover voltages under wet conditions are approximately the same, due to a significant percentage drop in the negative polarity impulse level. The probability distribution of the $\mathrm{V}_{50}$ impulse flashover levels for aged insulator string sections is shown in Figure 6. Comparing Figures 5 and 6, the main change with aging can be seen to be the decrease of negative polarity flashover voltages, to the level of positive polarity values. As shown in Table 1, the ratio of the difference in negative and positive wet impulse values over the difference in negative and positive dry impulse values become markedly reduced after aging.

Table 1. $250 \mu \mathrm{s} / 2.5 \mathrm{~ms}$ impulse flashover statistics for new and fieldaged insulators under dry and wet conditions. All voltages are in $\mathrm{kV}$.

\begin{tabular}{|l|l|l|l|l|l|l|l|l|}
\cline { 2 - 8 } \multicolumn{1}{c|}{} & \multicolumn{4}{c|}{ New } & \multicolumn{4}{c|}{ Field-aged } \\
\cline { 2 - 9 } \multicolumn{1}{c|}{} & $\mathrm{V}_{50}$ & $\sigma$ & Max & Min & $\mathrm{V}_{50}$ & $\sigma$ & Max & Min \\
\hline $\begin{array}{l}\text { A: } \\
\text { +'ve dry }\end{array}$ & 638 & 21 & 659 & 618 & 603 & 15 & 636 & 587 \\
\hline $\begin{array}{l}\text { B: } \\
\text { +'ve wet }\end{array}$ & 534 & 16 & 545 & 516 & 532 & 22 & 564 & 498 \\
\hline $\begin{array}{l}\text { C:- } \\
\text {-'ve dry }\end{array}$ & 825 & 8 & 832 & 817 & 800 & 24 & 828 & 758 \\
\hline $\begin{array}{l}\text { D: } \\
\text {-'ve wet }\end{array}$ & 593 & 11 & 603 & 581 & 539 & 28 & 574 & 500 \\
\hline $\begin{array}{l}\text { C-A } \\
\text { D - }\end{array}$ & 187 & 24 & 214 & 168 & 196 & 31 & 234 & 150 \\
\hline D-B & 59 & 20 & 78 & 39 & 7 & 14 & 26 & -14 \\
\hline $\begin{array}{l}\text { Difference } \\
\text { A\&B (\%) }\end{array}$ & 16.3 & 1.7 & 17.8 & 15 & 11.9 & 2.5 & 16.5 & 9.1 \\
\hline $\begin{array}{l}\text { Difference } \\
\text { C\&D (\%) }\end{array}$ & 28.2 & 1.8 & 29.7 & 26 & 33 & 5.3 & 38.6 & 24.9 \\
\hline
\end{tabular}




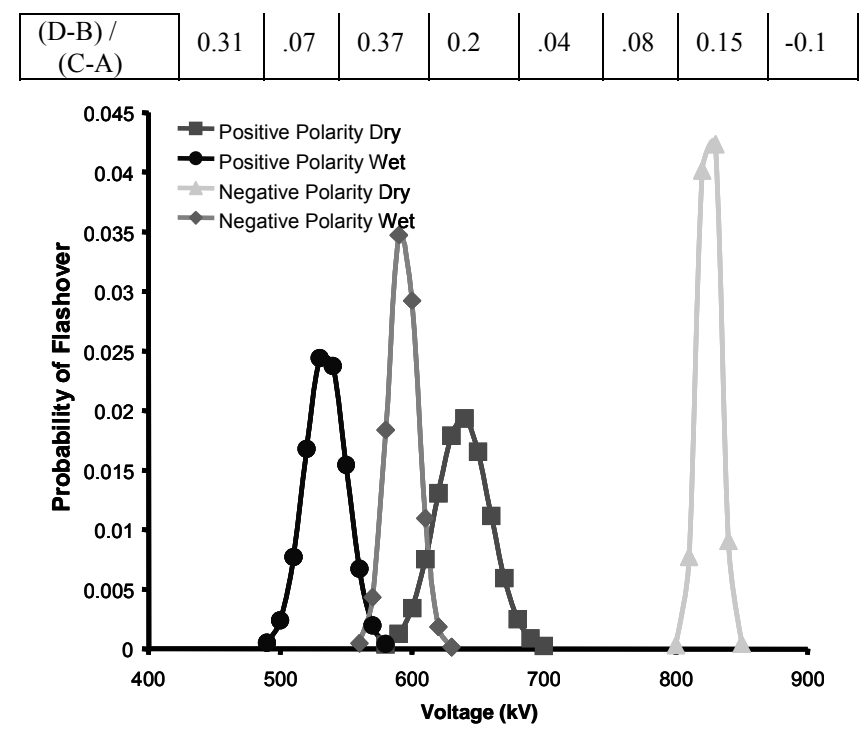

Figure 5. Statistical variation in impulse flashover levels for new insulators.

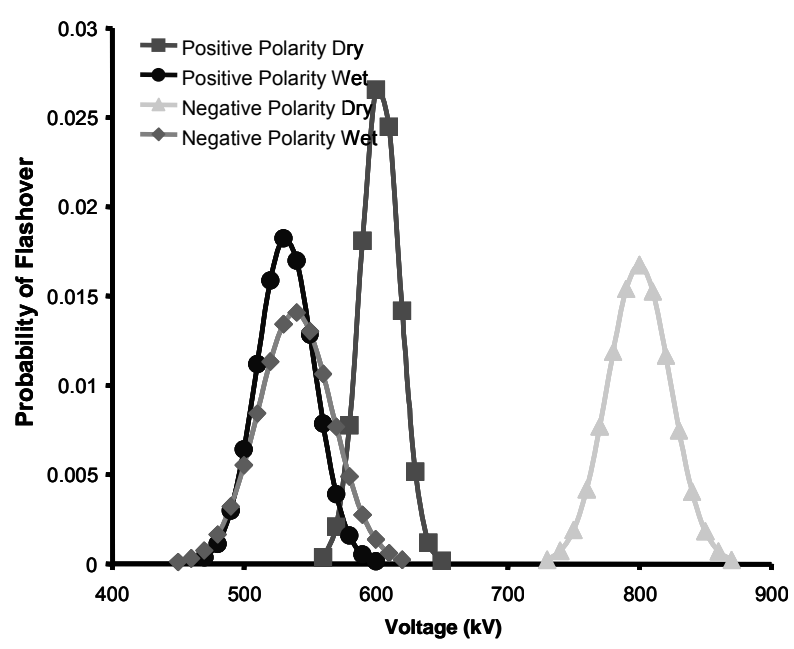

Figure 6. Statistical variation in impulse flashover levels for field-aged insulators.

For the field-aged insulators, the absence of any difference between the positive and negative polarity impulse level may be attributed to the loss in hydrophobicity of the material surface. It follows that flashover is due to conduction through a continuous water path, rather than through the air. No correlation between the hydrophobicity measurements and the distribution of impulse flashover levels could be determined with the location of the tests along the string (i.e. the top middle or bottom $1 / 3$ ).

\subsection{AC Withstand / Flashover Investigations}

$\mathrm{AC}$ withstand and flashover tests have been performed using a $800 \mathrm{kV} \mathrm{1A} \mathrm{Ferranti} \mathrm{/} \mathrm{Haefely} \mathrm{cascaded} \mathrm{resonance}$ transformer set. To limit the magnitude of the leakage currents a $1 \mathrm{M} \Omega$ high voltage water resistor was placed in series with the output of the transformer and the bottom of the insulator string. AC flashover investigations were performed on the insulator sections by ramping up the voltage at a rate of $10 \mathrm{kV} / \mathrm{s}$ until flashover. The ac flashover level was defined from the average of 10 flashovers.

$\mathrm{AC}$ withstand tests were performed by increasing the system voltage to a level of $15 \%$ below the ac flashover voltage and a withstand test was performed for the duration of 1 minute. The system voltage was then systematically increased in increments of $1 \%$ and the withstand process was repeated. If a flashover occurred in the duration of the 1 minute withstand, the test was repeated at the same voltage level. Should 2 flashovers occur at the same test voltage, then the withstand level was defined from the voltage level at which 2 subsequent flashover events didn't occur. Both measurements were compensated for the air density (temperature and pressure) according to [7].

Table 2 shows the ac flashover and withstand characteristics for the new and field-aged insulators. A larger percentage decrease from dry to wet conditions in both the ac flashover and ac withstand levels was apparent for the field-aged insulators, compared to the new insulators. It is also apparent that there is a larger difference between the wet ac flashover voltage and withstand voltages for the field-aged insulators, in comparison to the new insulators. As with the impulse flashover testing, no correlation has been found between the hydrophobicity measurements and the distribution of ac flashover / withstand levels down the insulator string.

\subsection{AC Leakage Current Investigations}

Leakage current measurements were performed using the $800 \mathrm{kV} 1 \mathrm{~A}$ Ferranti / Haefely cascaded resonance transformer, without the $1 \mathrm{M} \Omega$ ballast resistor in the circuit. Current waveforms were digitally captured using a $1 \mathrm{k} \Omega$ resistor in series with the top (earthed) end of the insulator, whilst voltage waveforms were captured from the $800 \mathrm{kV}$ divider connected to the transformer set. AC conductivity testing was performed at a range of voltages up to $100 \mathrm{kV}_{\mathrm{RMS}}$, well below the flashover voltage. Since

Table 2. ac flashover and withstand statistics for new and field-aged insulators under dry and wet conditions. All numbers are in $\mathrm{kVrms.}$

\begin{tabular}{|l|l|l|l|l|l|l|l|l|}
\cline { 2 - 9 } \multicolumn{1}{c|}{} & \multicolumn{4}{c|}{ New } & \multicolumn{4}{c|}{ Field-aged } \\
\cline { 2 - 9 } \multicolumn{1}{c|}{} & $\mathrm{V}_{50}$ & $\sigma$ & Max & Min & $\mathrm{V}_{50}$ & $\sigma$ & Max & Min \\
\hline $\begin{array}{l}\text { A:- dry } \\
\text { flashover }\end{array}$ & 489 & 31 & 516 & 456 & 466 & 18 & 494 & 440 \\
\hline $\begin{array}{l}\text { B:- wet } \\
\text { flashover }\end{array}$ & 438 & 24 & 466 & 423 & 400 & 13 & 419 & 383 \\
\hline $\begin{array}{l}\text { C:- dry } \\
\text { withstand }\end{array}$ & 466 & 36 & 500 & 429 & 451 & 16 & 481 & 429 \\
\hline $\begin{array}{l}\text { D:- wet } \\
\text { withstand }\end{array}$ & 421 & 28 & 453 & 404 & 381 & 10 & 399 & 367 \\
\hline A - C & 24 & 6 & 28 & 16 & 15 & 3 & 20 & 11 \\
\hline B - D & 17 & 3 & 19 & 13 & 19 & 7 & 30 & 10 \\
\hline $\begin{array}{l}\text { Difference } \\
\text { A\&B (\%) }\end{array}$ & 10.4 & 3.6 & 14.3 & 7.2 & 14.1 & 4.2 & 20.5 & 8.7 \\
\hline
\end{tabular}




\begin{tabular}{|l|l|l|l|l|l|l|l|l|}
\hline $\begin{array}{l}\text { Difference } \\
\text { C\&D (\%) }\end{array}$ & 9.5 & 3.7 & 13.3 & 5.8 & 15.6 & 3.2 & 20.3 & 11.4 \\
\hline
\end{tabular}

the $400 \mathrm{kV}$ (231 kV line to ground) insulator strings have been tested in $1 / 3$ sections, this is $25 \%$ above the nominal rated voltage of $80 \mathrm{kV}$ for the section.

Figure 7 shows voltage and current waveforms for a field-aged insulator mid- $1 / 3$ section, under dry test conditions. From this figure, it is apparent that the insulator presents a capacitive load, with about a $90^{\circ}$ phase shift between the current and voltage waveforms. The magnitude of the currents is determined both from the capacitive load of the insulator and also from stray capacitively coupled currents from supporting frameworks. Similar

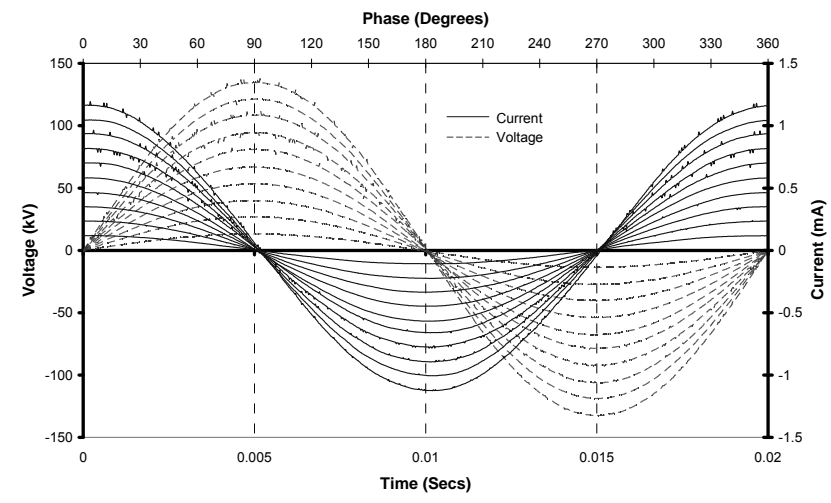

Figure 7. Current and voltage for a field-aged insulator section under dry test conditions.

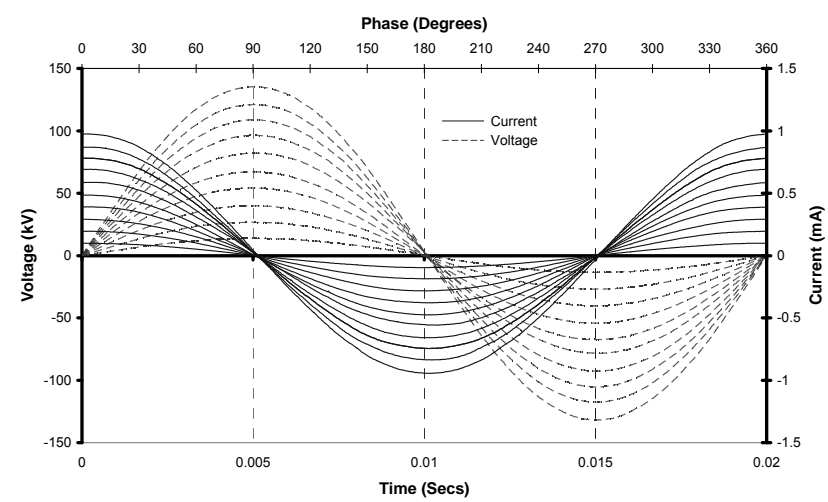

Figure 8. Current and voltage for a new insulator mid- $1 / 3$ section under wet test conditions.

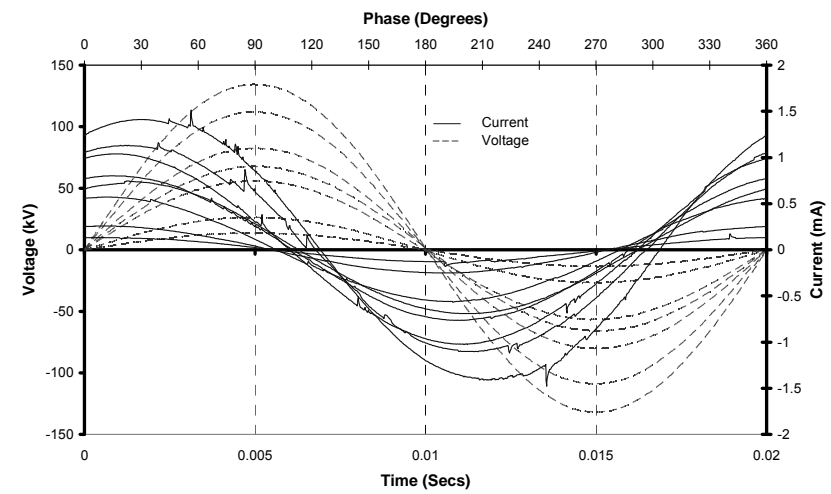

Figure 9. Current and voltage for a field-aged insulator top- $1 / 3$ section under wet test conditions.

characteristics are apparent for other field-aged and new insulator sections under dry conditions.

Figure 8 shows current and voltage waveforms for a new insulator mid $-1 / 3$ string section tested under wet conditions. From this figure, it is apparent that the insulator still presents a capacitive load, with approximately a $90^{\circ}$ phase shift between the current and voltage waveforms. Figures 9 -11 show the top, mid- and bottom- $1 / 3$ sections of a typical field-aged insulator string. From these figures, deterioration in the electrical performance of the insulators is evident, which results from a deterioration in hydrophobicity along the insulator string.

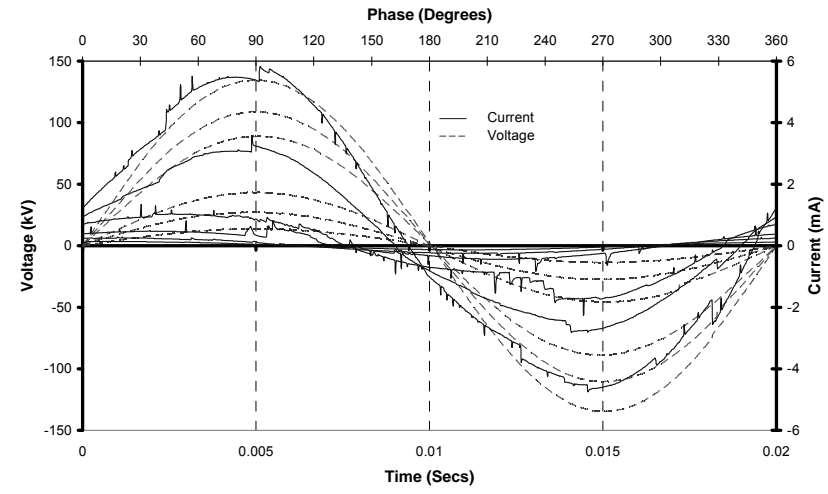

Figure 10. Current and voltage for a field-aged insulator mid- $-1 / 3$ section under wet test conditions.

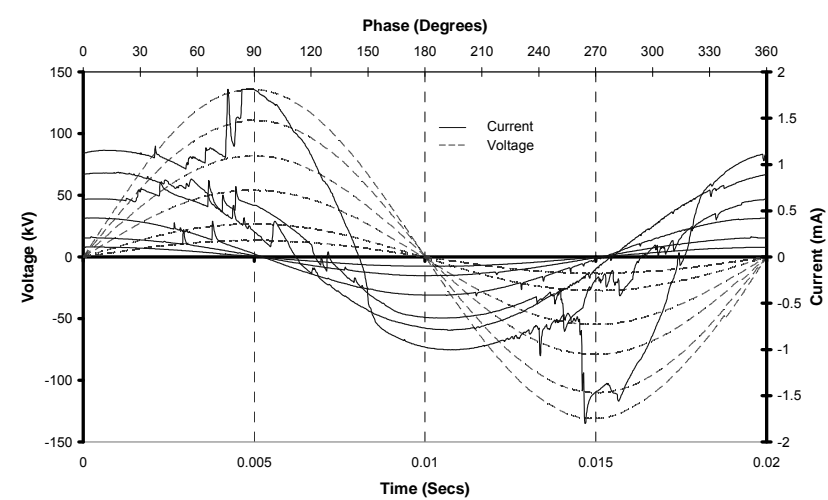

Figure 11. Current and voltage for a field-aged insulator bottom- $1 / 3$ section under wet test conditions.

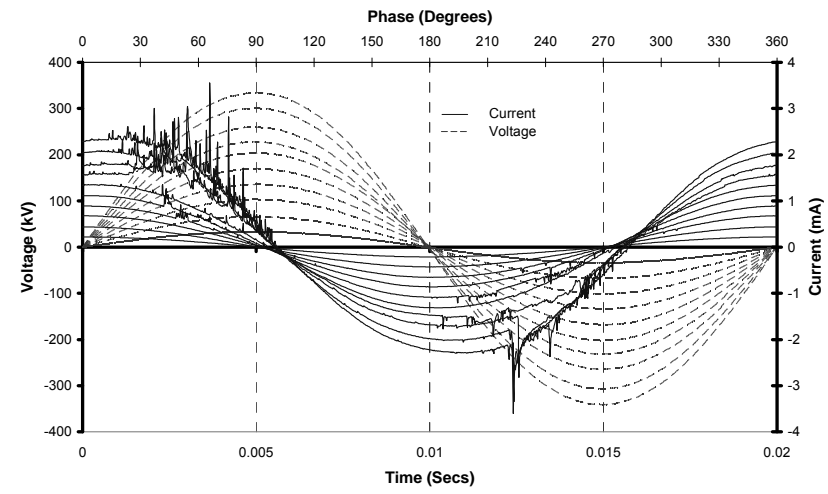


Figure 12. Current and voltage for a full field-aged insulator string under wet test conditions.

Figure 9 shows a top- $1 / 3$ section of a field-aged string, tested under wet conditions, and indicates that at low voltages, the current waveform is about 90 degrees out of phase with the voltage waveform. However, at voltages higher than $30 \mathrm{kV}$, a phase shift in the current waveform is evident, with a small degree of harmonic distortion. The magnitudes of the currents, however, are similar to those which were observed for the new insulator string.

Figure 10 shows the voltage and current waveforms for a mid- $1 / 3$ section of a field-aged insulator string, tested under wet conditions. In this section, it is evident that higher active currents (i.e. currents in-phase with the voltage) are flowing across the surface of the insulator string. At very low voltages, of around $10 \mathrm{kV}$ the current waveform is approximately $60^{\circ}$ out of phase with the voltage waveform. As the voltage is increased, the phase difference between the current and voltage waveform is decreased and the magnitude of the current increases non-linearly. At a voltage of $100 \mathrm{kV}$ the magnitude of the current flowing across the surface of the insulator is approximately 2.5 times the magnitude of the current of either the top or bottom-sections of the field-aged insulator. Erratic harmonic distortions to the current waveform are also present indicating that the current flow is not constant and some form of dry-band arcing process is taking place.

Figure 11 shows the current and voltage waveforms of a bottom- $-1 / 3$ section of a field-aged insulator string. Similar to the top section, the current waveforms are approximately $90^{\circ}$ out of phase with the voltage waveforms at low voltages of up to $30 \mathrm{kV}$, with a small phase shift at voltages above $30 \mathrm{kV}$. Harmonic distortions to the current waveforms, associated with arcing, are present at voltages of $30 \mathrm{kV}$ and above, the degree of which increase as the voltage is increased. The magnitude of the currents are again similar to that of a new insulator string.

Figure 12 shows the voltage and current waveforms for the full insulator string tested up to a working voltage of $250 \mathrm{kV}(231 \mathrm{kV}$ being the nominal operating voltage of the string) under wet spray conditions. Despite high degrees of conduction being observed in Figure 10, for the mid-1/3 section of an insulator string, little high active current flow is evident in the full string. At voltages up to $100 \mathrm{kV}$, the current remains virtually 90 degrees out of phase with the voltage waveform, with a small degree of phase shift at higher voltages when a degree of distortion is also evident due to discharge activity.

Table 3. EDX results along the string. The columns $\mathrm{N}$ and $\mathrm{S}$ refer to measurements from the north- and south-facing surfaces.

\begin{tabular}{|c|c|c|c|c|c|c|c|c|}
\hline \multirow{4}{*}{$\begin{array}{c}\text { Atom } \\
\%\end{array}$} & \multicolumn{5}{|c|}{ Shed Material } & \multicolumn{3}{|c|}{ Core Material } \\
\hline & \multirow{3}{*}{ New } & \multicolumn{4}{|c|}{ Field-aged } & \multirow{3}{*}{ New } & \multicolumn{2}{|c|}{ Field-aged } \\
\hline & & \multicolumn{2}{|c|}{ Top } & \multicolumn{2}{|c|}{ Bottom } & & \multirow[b]{2}{*}{$\mathrm{N}$} & \multirow[b]{2}{*}{ S } \\
\hline & & $\mathrm{N}$ & $\mathrm{S}$ & $\mathrm{N}$ & $\mathrm{S}$ & & & \\
\hline $\mathrm{C}$ & 38 & 43 & 34 & 38 & 34 & 54 & 49 & 44 \\
\hline $\mathrm{O}$ & 38 & 40 & 46 & 39 & 44 & 34 & 35 & 37 \\
\hline $\mathrm{Al}$ & 8 & 3 & 7 & 5 & 6 & 3 & 3 & 0 \\
\hline $\mathrm{Si}$ & 14 & 13 & 12 & 16 & 14 & 9 & 12 & 18 \\
\hline
\end{tabular}

\section{MATERIAL TESTING}

Three of the field-aged insulators were studied using EDX and FTIR techniques. EDX analysis is a technique which can be employed to study the percentage of chemical elements present on the surface of the insulator. FTIR analysis can be used to determine the type and amount of molecular bonds present on the surface of the insulator. Through studying the data from both of these analyses, the degree of aging may be determined by the degree of change. More specifically, the effects of aging through environmental, electrical and thermal stresses can be related to oxidization effects and loss in hydrophobicity of the outer polymeric material. For example, methyl groups, which are attached to the siloxane backbone, are expected to be oxidized into $\mathrm{O}-\mathrm{H}$ groups, which are hydrophilic in nature [8].

EDX analysis was undertaken using a Hitachi SM-2000 at $15 \mathrm{kV}$. The penetration beam depth into the sample is about $3 \mu \mathrm{m}$. Table 3 shows the average oxygen percentage on the top and bottom surface of sheds.

From Table 3, it is evident that the southern-facing top surfaces of the insulator sheds show higher oxygen concentrations than on other surfaces. The core region did not show differences of oxygen percentage along the string, with the exception of the shed near the HV end-fitting, where the values of high oxidation may reflect the chemical constitution of contaminant layer.

FTIR analysis was performed using a Perkin Elmer Autoimage FTIR microscope system. The sum of 100 scans was used and the resolution of the spectrometer was $5 \mathrm{~cm}^{-1}$. Table 4 shows a comparison of FTIR data on the north- and south-facing surfaces.

From Table 4, it is evident that the polymeric groups corresponding to $\mathrm{Si}-\mathrm{CH}_{3}$ bonds have been reduced, whilst the groups corresponding to the $\mathrm{O}-\mathrm{H}$ bonds have all been increased, due to the effects of aging. The bottom shed surfaces generally had higher concentrations of Si-O-Si bonds than the top surfaces. A reduced level of such bonds indicates chain scission resulting from high energy damage on the top surfaces, and some form of arcing activity.

In this study, the oxidization is more pronounced on the sheds than on the sheath. $\mathrm{O} / \mathrm{C}$ ratios are also higher on the south side of the sheds indicating a greater tendency to form $\mathrm{O}-\mathrm{H}$ groups. This increased oxidative state is consistent with the decreased hydrophobicity witnessed.

Table 4. FTIR results along the string. The columns $\mathrm{N}$ and $\mathrm{S}$ refer to measurements from the north- and south-facing surfaces.

\begin{tabular}{|c|c|c|c|c|c|c|c|c|}
\hline \multirow{4}{*}{ Bond } & \multicolumn{5}{|c|}{ Shed Material } & \multicolumn{3}{|c|}{ Core Material } \\
\hline & \multirow{3}{*}{ New } & \multicolumn{4}{|c|}{ Field-aged } & \multirow{3}{*}{ New } & \multicolumn{2}{|c|}{ Field-aged } \\
\hline & & \multicolumn{2}{|c|}{ Top } & \multicolumn{2}{|c|}{ Bottom } & & \multirow[b]{2}{*}{$\mathrm{N}$} & \multirow[b]{2}{*}{$\mathrm{S}$} \\
\hline & & $\mathrm{N}$ & $\mathrm{S}$ & $\mathrm{N}$ & S & & & \\
\hline $\mathrm{OH}$ & 0.1 & 0.3 & 0.3 & 0.1 & 0.3 & 0.1 & 0.2 & 0.2 \\
\hline $\mathrm{Si}-\mathrm{CH}_{3}$ & 0.4 & 0.3 & 0.2 & 0.3 & 0.2 & 0.4 & 0.3 & 0.3 \\
\hline $\mathrm{Si}-\mathrm{O}-\mathrm{Si}$ & 1.1 & 0.6 & 0.5 & 1.0 & 0.6 & 1.1 & 1.1 & 0.7 \\
\hline $\mathrm{Si}\left(\mathrm{CH}_{3}\right)_{2}$ & 0.9 & 0.4 & 0.2 & 0.8 & 0.4 & 0.9 & 0.9 & 0.6 \\
\hline
\end{tabular}


The behavior, shown in Tables 3 and 4, is in general agreement with other studies using EDX and FTIR on service-aged and laboratory-aged samples comparing northand south-facing sides described in [9] for EPDM insulators, which were experiencing unexplained outages. More details on the measurements summarized in this paper are to be found in [6].

\section{DISCUSSION}

Visual observations have shown that asymmetrical aging has taken place along the field-aged insulators, the nature of which is ascribed to environmental aging processes, particularly UV radiation. By studying the variation of contact angle, the interaction of electrical activity and environmental conditions are revealed. Contact angles on both the top and bottom surfaces of the sheds were higher on the north side than on the exposed south side where material was discolored. Such a north-south difference has been reported previously on poorly performing HV EPDM composites in the northern hemisphere and medium voltage (MV) EPDM composites in the southern hemisphere [911]. In each case the sun-facing side showed a bleaching effect. Clear differences exist between the top and bottom surfaces of the sheds. The hydrophobicity of the sheds tends to a minimum in the centre of the string rather than at the $\mathrm{HV}$ end, counter to other reports $[9,12,13]$. If surface condition controls the performance of the insulator, this will be determined by the south-facing bottom surfaces after the asymmetric aging has developed. This is because the top and bottom surfaces can be considered as seriesconnected hydrophobic and hydrophilic regions, and the low conductivity hydrophilic regions will control the conductive properties of the complete insulator.

UV radiation and discharge activity degrade the polymeric groups in different ways. The bonding energy of $\mathrm{Si}-\mathrm{C}$ is $301 \mathrm{~kJ} / \mathrm{mol}$, and that of Si-O is $447 \mathrm{~kJ} / \mathrm{mol}$ so solar radiation can break the former but not the latter. Electrical discharges have the energy to break both bonds. Aluminium trihydrate (ATH) filler may also decompose during discharge activity, but is stable under UV exposure, however measurements of surface concentration of aluminium by EDX have been found to be variable and difficult to interpret, here and elsewhere.

Although reports of rotational asymmetry resulting from artificial tests are not found in the literature, general changes to molecular bonds, related to different aging mechanisms have previously been observed. It has been shown for insulators aged in a salt-fog chamber through dry-band arcing, that an increase in oxygen concentration and a decrease in carbon concentration was observed [8]. FTIR spectroscopy showed an insulator aged in an acid rain chamber [14] to have a reduction in the amount of $\mathrm{CH}_{3}$ bonds on the surface of the polymer, without any change in $\mathrm{Si}-\mathrm{O}-\mathrm{Si}$ concentrations. Further information and case studies on the change in polymer chemistry of the surface of the insulator material through different aging mechanisms are cited in [6].
From the material study, the oxidation is more obvious on the south sides than north sides, especially in the middle section of the string. The oxygen percentages are higher on the south side of sheds indicating a greater tendency to form $\mathrm{O}-\mathrm{H}$ groups on the south side of the sheds. That is also supported by the result of FTIR spectroscopy which manifested as higher Si-OH bands and reduced Si-O-Si bands. Differences between top and bottom surfaces along the string can be seen from the FTIR results, athough EDX did not show such a distinction.

Combining the material analysis with the hydrophobicity analysis, the visual observations and the topography of the line, it may be suggested that the southern-facing insulator surfaces see a different environment from the northernfacing surfaces. It has previously been reported [9] that UV radiation is a key aging agent leading to the degradation of silicone rubber insulator materials. It is this oxidisation process that is responsible for the loss of hydrophobicity of the material. Exposure to UV radiation coupled with the effect of other electrical and environmental aging factors may enhance this effect [10].

The change in the impulse level for the insulators under switching surge impulse conditions of the insulators, under wet spray conditions, was greatest for negative polarity. For the field-aged insulators, the change in the hydrophobicity, through processes of oxidization, reduced the negative polarity impulse level to be indistinguishable from the positive polarity impulse level. This was not so for the new insulators, which had a high degree of hydrophobicity, where the negative polarity impulse level was still significantly higher than the positive polarity impulse level, under wet spray conditions. The link between changes in surface chemistry and hydrophobicity suggest the reduced level impulses flashovers took place down the southern facing sides of the insulators, although this has not been confirmed. Differences between the impulse flashover characteristics of the $1 / 3$-sections, representing different regions of the insulator string, were small. This may be due to the length of the insulator string sections artificially creating the situation where the physical air-gap still influences the breakdown process rather than it being dominated by the insulator surface condition.

The average ac flashover / withstand tests are reduced through field-aging by $5 \%$ and $10 \%$ respectively. These reductions are not considered significant given the spread of results. Also no relationship between withstand / flashover levels of the $1 / 3$-sections and a variation in hydrophobicity / changes in surface chemistry down the length of the field-aged insulator strings was identified. Dry/wet flashover tests show only small differences among flashover voltage among insulator sections. This is consistent with no indication of the insulators performing poorly in service, before decommissioning.

The electrical measurements showed that aging of the insulators promote the flow of active currents over the material surfaces. From material analysis of samples on the north and south faces, it can be suggested that the leakage currents are more highly concentrated along the hydrophilic 
south-facing surfaces. If this is the case, this may lead to a difference in the electric field distribution in the insulator between the north- and south-facing sides. Further electrical aging on the south-facing surfaces may then occur at an accelerated rate, compared to the north-facing surfaces.

The ac conductivity characteristics show that the deterioration in the hydrophobicity of the insulator string is associated with the presence of active currents flowing down the insulator string, under wet test conditions. For the new insulator strings, the high degree of hydrophobicity prevented the flow of any active currents (Figure 8 ). In this case the mid- $1 \frac{1}{3}$ had lowest contact angles (Figures 2 and 3 ) and the highest active current. The top and bottom ends of the insulators showed intermediate levels of conductivity, consistent with the contact angles measured between those in the most aged and new conditions. Because of the inhomogeneous nature of the hydrophobicity more work is required to quantify this relationship.

\section{CONCLUSION}

Measurements of hydrophobicity and visual observations of the surface of field-aged $400 \mathrm{kV}$ silicone rubber composite insulators show variations from end-to-end and circumferentially. The sheds near HV and LV end-fittings had accumulated more deposits than the sheds away from both the ends. However, the maximum reduction in hydrophobicity is seen in the mid-section of the string rather than at the $\mathrm{LV}$ or $\mathrm{HV}$ end. Within one insulator shed the contact angle could vary $11^{\circ}$ across its face from north to south. The side of the insulator which faced the sun and prevailing winds from the sea aged faster, as measured by loss of color and reduced contact angle with water. The top surface of the sheds also had a lower contact angle than the bottom surface.

It is suggested that the location of the insulator is critical to the type of aging which develops. In particular the impact of solar radiation may be different with distance from the equator. The increase in asymmetry faced with distance from the equator may make this more onorous despite lower intensity levels.

Electrical investigations have identified that the hydrophilic surfaces on the insulator can promote active leakage currents over the surface of the insulator in the presence of a wet spray. In addition these investigations have indicated that hydrophilic materials also promote discharge activity in the presence of a wet spray. The degradation has been quantified using material techniques among which EDX and FTIR have proved to be the most effective tools. The analysis has shown the aging is an oxidation process, resulting in the formation of $\mathrm{Si}-\mathrm{OH}$ groups and loss of hydrophobicity.

Electrical testing of the field-aged insulators under dry and wet conditions illustrate that the hydrophilic regions of the string promote the flow of active leakage currents over their surfaces, which may lead to a decrease in the ac withstand and flashover levels of the insulator.
The relative values of positive and negative flashover voltage have been shown to change significantly as a result of aging. The values become indistinguishable after aging as opposed to a $10 \%$ difference in the new insulators. Such a measure may provide a valuable non-destructive condition assessment tool, revealing aging in otherwise perfectly health insulators, which are at an early stage of deterioration. This suggestion needs verification on other insulator types with different histories.

\section{ACKNOWLEDGMENT}

The authors are grateful to National Grid for the support of this research, and for their permission to publish.

\section{REFERENCES}

[1] J. Mackevich and M. Shah, "Polymer Outdoor Insulating Materials. Part I: Comparison of Porcelain and Polymer Electrical Insulation", IEEE Electr. Insul. Mag., Vol. 13, Issue 3, pp. 5-12, 1997.

[2] V.K. Agarwal, "Aging of Multistressed Polymeric Insulators", IEEE Trans. Electr. Insul., Vol. 24, pp. 741-764, 1989.

[3] A. Bradwell and J.C.G. Wheeler, "Evaluation of Plastic Insulators for use on British Railways $25 \mathrm{kV}$ Overhead Line Electrification", IEE Proc. B, Electr. Power Appl., Vol. 129, pp. 101-110, 1982.

[4] S.M. Rowland, "Prevention of Dry-Band Arc Damage on ADSS Cables", IEEE Trans. Dielectr. Electr. Insul., Vol. 13, pp. 765-772, 2006.

[5] G.G. Karady, M. Shah and R.L. Brown, "Flashover Mechanism of Silicone Rubber Insulators used for Outdoor Insulation-I", IEEE Trans. Power Del., Vol. 10, pp. 1965-1971, 1995.

[6] Y. Xiong, S.M. Rowland, J. Robertson and R. Day, "Surface Analysis of Asymmetrically Aged $400 \mathrm{kV}$ Silicone Rubber Composite Insulators", IEEE Trans. Dielectr. Electr. Insul., Vol. 15 , pp. 763-770, 2008.

[7] IEC 60060-1 Ed 2 1989-11-15.

[8] S.-H. Kim, E.A. Cherney, R. Hackam and K.G. Rutherford, "Chemical Changes at the Surface of RTV Silicone Rubber Coatings on Insulators During Dry-Band Arcing", IEEE Trans. Dielectr. Electr. Insul., Vol. 1, pp. 106-123, 1994.

[9] R. Sundararajan, A. Mohammed, N. Chaipanit, T. Karcher and Z. Liu, "In Service Ageing and Degradation of $345 \mathrm{kV}$ EPDM Transmission Line Insulators in a Coastal Environment", IEEE Trans. Dielectr. Electr. Insul., Vol. 11, pp. 348-361, 2004.

[10] M.A.R.M. Fernando and S.M. Gubanski, "Performance of Nonceramic Insulators Under Tropical Field Conditions", IEEE Trans. Power Del., Vol. 15, pp. 355-360, 2000.

[11] E. Da Silva and S. M. Rowland, "In-Service Surface Degradation of MV Composite Insulators under Severe Environmental Conditions and Low Electric Stress", IEEE Conf. Electr. Insul. Dielectr. Phenomena (CEIDP), pp. 192-195, 2008.

[12] D. Birtwhistle, P Blackmore, A. Krivda, G. Cash and G. George, "Monitoring the Condition of Insulator Shed Materials in Overhead Distribution Networks", IEEE Trans. Dielectr. Electr. Insul., Vol. 6, pp. 612-619, 1999.

[13] H. Liu, G. Cash, D. Birtwhistle and G. George, "Characterization of a Severely Degraded Silicone Elastomer HV Insulator - an Aid to Development of Lifetime Assessment Techniques", IEEE Trans. Dielectr. Electr. Insul., Vol. 12, pp. 478-486, 2005.

[14] X. Wang, S. Kumagai, and N. Yoshimura, "Contamination Performances of Silicone Rubber Insulator Subjected to Acid Rain", IEEE Trans. Dielectr. Electr. Insul., Vol. 5 , pp. 909-916, 1998. 


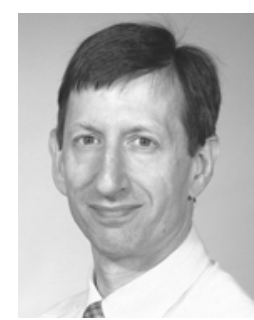

Simon M. Rowland (SM'07) was born in London, England. He completed the B.Sc. degree in physics at UEA and the Ph.D. degree at London University. He was awarded the IEE Duddell Premium in 1994 and became a FIEE in 2000. He has worked for many years on dielectrics and their applications. He has also been Operations and Technical Director of multinational manufacturing companies. He joined The School of Electrical and Electronic Engineering in The University of Manchester as a Senior Lecturer in 2003 and was appointed Professor of Electrical Materials in 2009. He is Vice-President Admin. of the IEEE Dielectric and Electrical Insulation Society.

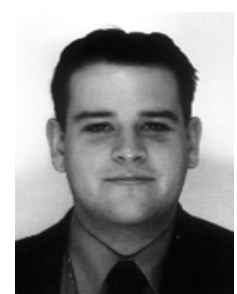

Jeff Robertson (M'02) was born in Liverpool, England. He completed both the B.Sc. and M.Eng. degrees in electrical and electronic engineering and Eng. D. at the University of Manchester. After spending many years in both academic and industrial related research, studying the development and aging of dielectric materials, he is currently working as the Technical Manager at company called M\&I Materials, based in Manchester. He is also an active committee Member of the IET in the Manchester Branch.

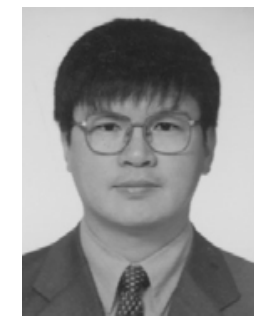

Yu Xiong (M’05) was born in Nanning, China. He completed the B.Sc. degree in electrical engineering at Wuhan University in 1993 and the M.Sc. degree at UMIST in 2004. He has worked for some years on power system design. He is currently a Ph.D. student at the University of Manchester investigating the aging mechanisms of composite polymeric insulator systems.

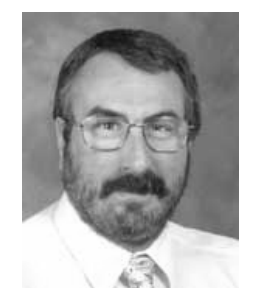

Richard Day was born in Bristol, England. He completed the B.Sc. degree in physics at Queen Mary College, University of London (now Queen Mary, London). He then studied the physics of materials for the MSc degree at Bristol University before returning to London University for the Ph.D. degree. He has worked on a number of materials including ceramic and polymer matrix composites. He joined the School of Materials at the University of Manchester in 1986. He is Director of the Northwest Composites Centre. 